\title{
Costello syndrome: natural history and differential diagnosis of cutis laxa
}

\author{
S J Davies, H E Hughes
}

\begin{abstract}
Costello syndrome is emerging as a better delineated condition and should be included in the differential diagnosis of cutis laxa in association with postnatal growth retardation and developmental delay. We present a further case of Costello syndrome which illustrates the natural history of this condition.
\end{abstract}

( $(\mathcal{M}$ Med Genet 1994;31:486-489)

Costello first described in 1971, and later in 1977 , two young children with similar features of poor postnatal growth, developmental delay, distinctive facies, and papillomata of the anterior nares. ${ }^{12}$ There were no further reports to allow more detailed delineation of the condition until Der Kaloustian $e t a l^{3}$ and Martin and Lyons Jones ${ }^{4}$ described two additional cases in 1991. Increasing awareness of this syndrome has led to a number of case reports ${ }^{5-8}$ and has opened debate on whether or not the new syndrome of multiple congenital anomaly with mental retardation and facio-cutaneousskeletal involvement described by Borochowitz et $a l^{9}$ in 1992 is in fact Costello syndrome. ${ }^{70-12}$

We would like to present a further patient with Costello syndrome who has been reported previously as case 7 in a series of seven children with "Congenital cutis laxa with retardation of growth and development" by Patton $e t ~ a l^{13}$ in 1987. Interestingly, case 5 of the same series has independently been reassessed and has also been diagnosed as having Costello syndrome. ${ }^{14}$

\section{Case reports}

A female infant was born at 39 weeks by spontaneous vaginal delivery with Apgar scores of 9 at one minute and 10 at five minutes. Both parents were healthy and nonconsanguineous with two healthy older sons. The mother was 24 and the father 32 years of age at the time of conception. Pregnancy was complicated by mild hypertension in the third trimester and the mother was aware that fetal movements were less than in her previous pregnancies. Birth weight was $3950 \mathrm{~kg}$ (90th centile), length $47 \mathrm{cms}(<10$ th centile), and head circumference $35 \mathrm{~cm}$ ( $>50$ th centile). Dysmorphic features as well as macroglossia and lax skin were noted at birth and chromosome studies showed a normal female karyotype $(46, \mathrm{XX})$. Hyperbilirubinaemia was present with a maximum level of $280 \mathrm{mmol} / \mathrm{l}$ on the fifth day. At 6 weeks of age the infant was investigated for failure to thrive. At that time, the head circumference was $37 \mathrm{~cm}$ ( $>50$ th centile), weight $3.48 \mathrm{~kg}$ (10th centile), and length $51 \mathrm{~cm}(<10$ th centile). She was noted to have a depressed nasal bridge, prominent low set ears, a large tongue, and bilateral single palmar creases. Poor subcutaneous fat with loose folds of skin were apparent and there was bilateral talipes equinovarus. No obvious cause for her failure to thrive was found other than very poor feeding requiring hourly spoon feeds.

At 8 months she was again investigated in the light of gross failure to thrive, dysmorphic features, and developmental delay (fig 1). She could not roll over or lift her head. Weight was $4.5 \mathrm{~kg}$ ( $<3 \mathrm{rd}$ centile), height $63 \mathrm{~cm} \quad(<3 \mathrm{rd}$ centile), while the head circumference was $41.5 \mathrm{~cm}$ (10th centile). A provisional diagnosis of leprechaunism was made though subsequently refuted on investigation. Hyperextensibility of joints with loose skin were noted (fig 1). A diagnosis of the syndrome of cutis laxa with ligmentous laxity and delayed development was made though it was noted that she had not had intrauterine growth retardation or congenital hip dislocation as in the previously described cases. ${ }^{15}$ A skin biopsy showed normal elastic tissue network with Halmi's stain and electron microscopy.

The bilateral talipes was treated initially with passive stretching and plaster of Paris. A good result was obtained in the right foot but there was considerable calcaneovarus and metatarsus varus on the left. When at the age of 2 years 6 months she was admitted for corrective surgery, the tight Achilles tendon was seen to be the major deforming force and elongation of the Achilles tendon and the tibialis posterior tendon was performed with spliting and transfer of the tibialis anterior tendon. Her weight at this time was $7.4 \mathrm{~kg}(<3 \mathrm{rd}$ centile), height $75 \mathrm{~cm}$ ( $<3$ rd centile), with relative macrocephaly, OFC $48 \mathrm{~cm}$ ( $<50$ th centile). Developmental delay was confirmed. Sparse curly hair, ptosis, left facial asymmetry, and delayed hypocalcified carious dentition were also noted ${ }^{13}$ (fig 2).

Subsequent development has been slow with day time continence at 5 years, night time continence at 8 years, and walking independently at 7 years. She attends a special school. The left foot developed a severe valgus deformity following surgery and at 8 years of age the tibialis anterior tendon was transferred to its original attachment.

Referral was made for genetic counselling at the age of 10 years 2 months (fig 3 ). On examination weight was $18 \mathrm{~kg}(<3 \mathrm{rd}$ centile), 

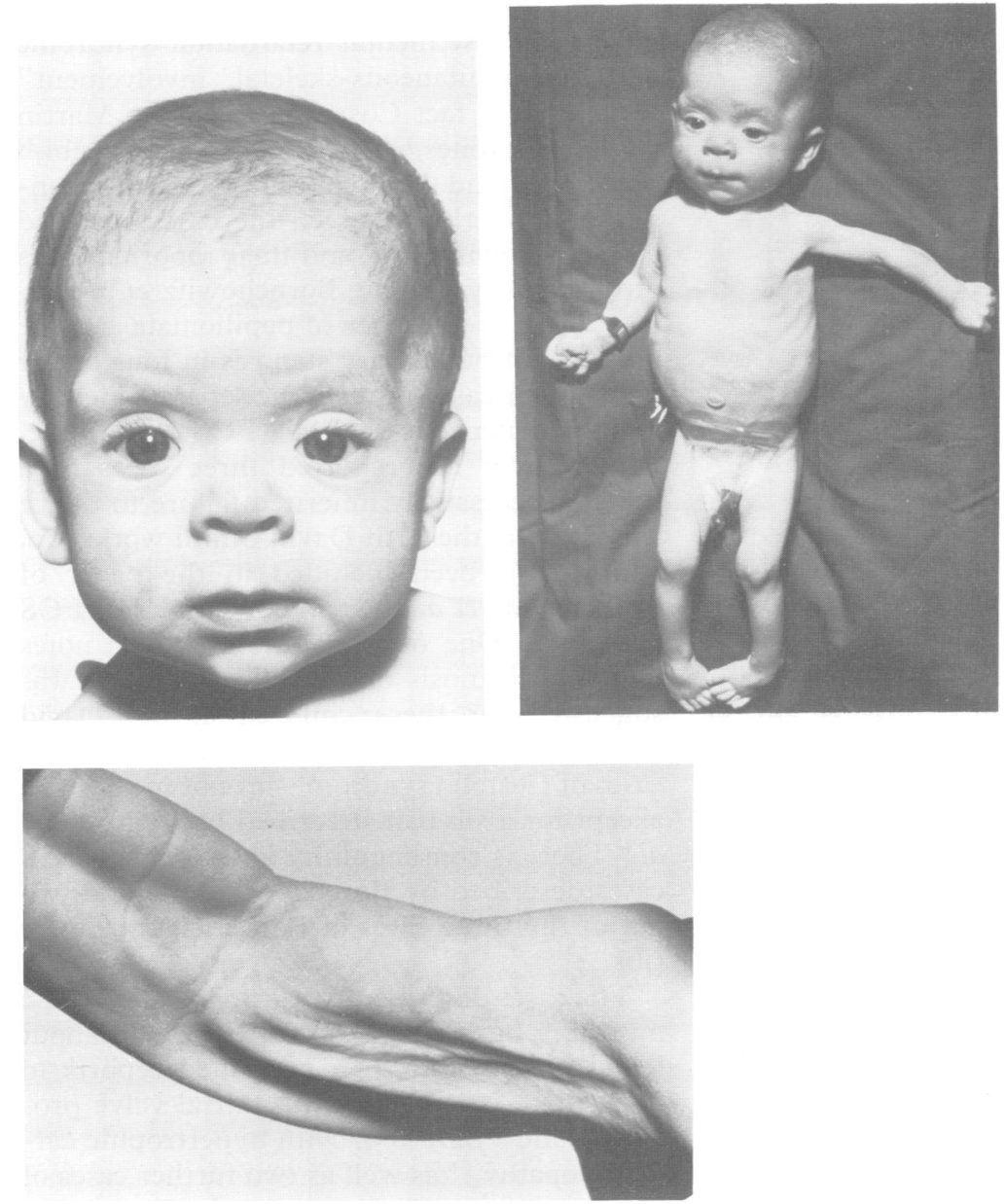

Figure 1 The face, whole body illustrating failure to thrive and bilateral talipes equinovarus, and lax skin of the patient aged 8 months.

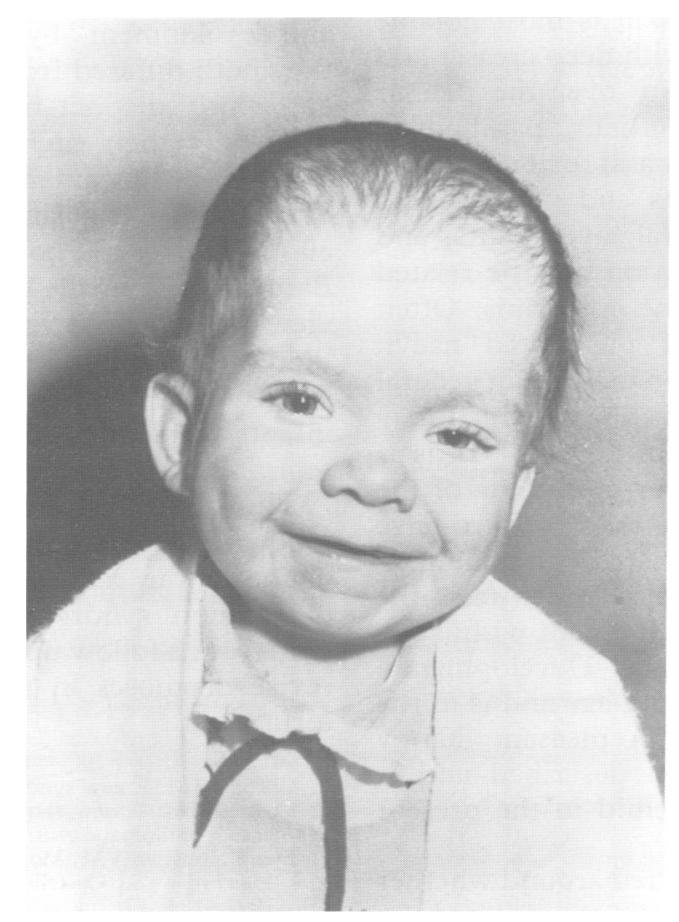

Figure 2 Facial appearance at 2 years 6 months.

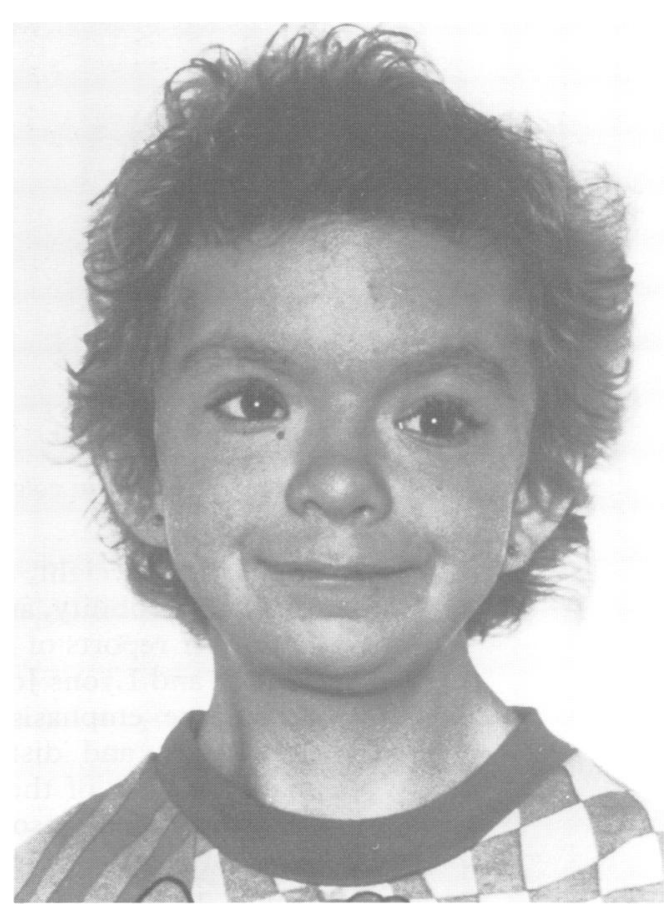

Figure 3 Facial appearance at 10 years 2 months.

height $123 \mathrm{~cm}$ ( $<3$ rd centile), and OFC $53 \mathrm{~cm}$ $(<50$ th centile). The hair was curly and sparse with poor growth. There was bilateral ptosis and myopia with horizontal nystagmus and convergent strabismus. Epicanthic folds were present giving an appearance of hypertelorism. There was no obvious papillomata at the nares but a papilloma was seen on the medial aspect of the right lower eyelid. The ears were posteriorly rotated with prominent helices and thickened lobes. A high arched palate, gingival hypertrophy, and ridged hypoplastic incisors were noted. There was retrognathia and the voice was low and hoarse. A pectus excavatum was present. A soft grade $2 / 6$ mid systolic murmur was heard at the lower left sternal edge and echocardiography showed a thickened ventricular septum suggestive of hypertrophic obstructive cardiomyopathy. The skin was soft generally, especially on the palms and soles, and loose over the abdomen and joints. There were no scars or bruising but several generalised pigmented naevi were present. Deep grooves were present on the palmar aspects of the hands and feet. The nails were hypoplastic and grew poorly. The joints, most noticeably the small joints of the hand, were hyperextensible with ulnar deviation. The feet were broad and the left foot was everted after surgery with the first toe curled underneath (fig 4). Nerve conduction studies were normal. She has a happy, sociable disposition and enjoys her special schooling. Assessment at 10 years showed a WISC of 45-56 (verbal score), 44-58 (performance), and 40-49 (full score).

\section{Discussion}

Costello originally reported two children with distinctive features of nasal papillomata, coarse facies, mental retardation, and growth retardation. ${ }^{12}$ The additional notable features were 


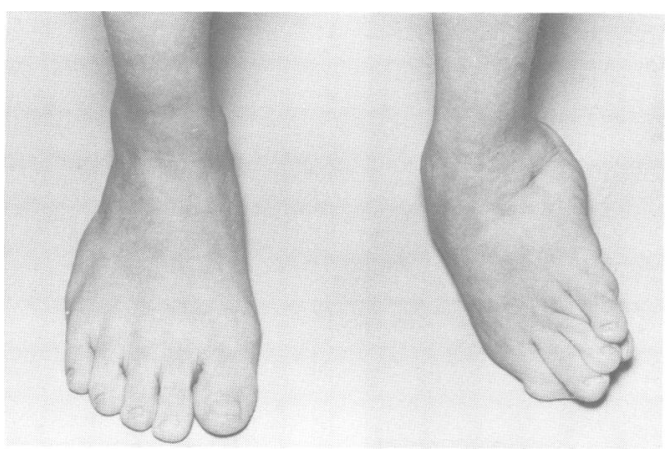

Figure 4 Persistent valgus deformity of left foot.

high birth weight, curly sparse hair, joint hyperextensibility, and tight Achilles tendons. The later reports of Der Kaloustian et $a l^{\beta}$ and Martin and Lyons Jones ${ }^{4}$ further delineate the phenotype emphasising the variable age of appearance and distribution of the papillomata. In view of the papillomata, loose skin, and absence of associated heart defect, Der Kaloustian et al emphasise that Costello syndrome is distinct from cardiofaciocutaneous (CFC) syndrome and Noonan syndrome despite some facial similarity, but suggest that there is sufficient phenotypic overlap between these syndromes that cases of Costello syndrome may have been misdiagnosed as Noonan or CFC in the past.

This present case serves to illustrate the natural history of this condition. As previously reported, the post natal onset of severe failure to thrive appears not to be related just to poor feeding as the infants continue to fail to thrive despite an improvement in caloric intake and gastric feeding. ${ }^{8}$ Interestingly, the diagnosis of leprachaunism has been considered in several cases. ${ }^{58}$ The head appears large in comparison to the reduced body weight and height. With age, the hair is curly, slow growing, and brittle and the nails similarly are soft and slow to grow. The laxity of the skin is most notable over the hands and feet, with deep creases and a thickened velvety quality over the palmar and plantar surfaces. Initially papillomata were described in the perinasal region but they can occur at various ages and various sites including perianal, perioral, over joints, and generalised. This distribution may be related to repetitive friction of the epidermis. Often there is development of pigmented naevi, acanthosis nigricans, and an increase in general pigmentation. The voice is hoarse which may be because of papillomata of the vocal cords as found by Zampino et $a l^{8}$ or crumpling of the cords as described by Say et al. ${ }^{5}$ There have been descriptions of associated epitheliomata ${ }^{4}$ and a ganglioneuroblastoma, ${ }^{8}$ which raise the possibility of tumour development within tissues of neural crest origin. Developmental delay becomes apparent with age and is in the mild to moderate range. A pleasant, happy nature has regularly been described and is certainly the case in the child in the present report.

Debate has recently centred around whether some, if not all, of the cases reported by Borochowitz et $a l^{9}$ as a "New multiple congen- ital anomalies: mental retardation syndrome with facio-cutaneous-skeletal involvement" (FCS) are in fact Costello syndrome. Martin and Lyons Jones, ${ }^{10}$ Der Kaloustian, ${ }^{11}$ Teebi, ${ }^{12}$ and Philip and Mancini ${ }^{7}$ emphasise the considerable overlap between the cases reported by Borochowitz et $a l^{9}$ and their reported cases of Costello syndrome. Borochowitz et al ${ }^{16}$ respond that the absence of papillomata and the presence of pulmonary stenosis in four out of five of their cases confirm the separate identity of facio-cutaneous-skeletal (FCS) syndrome. Berberich et $a l^{17}$ reported three cases of a possibly recessively inherited failure to thrive syndrome at the 11th David Smith workshop, which have been included in the paper of Borochowitz et al as further examples of FCS syndrome. One of the authors $(\mathrm{HEH})$ notes that the diagnosis of Costello syndrome was suggested for these children at the David Smith presentation in 1990 . The published cases of Costello syndrome have been sporadic except for a sib pair described by Zampino et $a l .{ }^{8}$ There is consanguinity in two of the FCS cases described by Borochowitz et al and two out of the three cases of Berberich et al were sibs.

The cases described by Costello had systolic murmurs but there is no further detail about their cardiac status. In published reports to date, there is one case with mitral valve prolapse, ${ }^{4}$ one VSD,${ }^{6}$ four with hypertrophic cardiomyopathy, ${ }^{78}$ as well as two further cases of hypertrophic cardiomyopathy in those presented by Berberich et $a l^{17}$ and the four examples of pulmonary stenosis in the FCS patients of Borochowitz et al. ${ }^{9}$ This case provides a further example of the development of hypertrophic cardiomyopathy.

Interestingly both our case and the case recently reviewed by Patton and Baraitser ${ }^{14}$ were initially reported as having the syndrome of "congenital cutis laxa with retarded growth and development" by Patton et al ${ }^{13}$ in 1987 but they both differed from the other cases of this apparently distinct recessively inherited syndrome by their high birth weights and the absence of intrauterine growth retardation. Skin biopsy has since confirmed a normal elastin network in both the case of Patton and Baraitser and in the patient reported here. In view of the revised diagnosis in these two cases there is obviously room to consider Costello syndrome in the differential diagnosis of other infants with lax skin, severe postnatal growth retardation, and developmental delay.

This case illustrates the importance of the follow up of dysmorphic children in order to delineate the natural history of "new" and uncommon syndromes and, just as importantly, such follow up allows an opportunity to revise diagnoses in the light of updated information.

1 Costello JM. A new syndrome. NZ Med f 1971;74:397.

2 Costello JM. A new syndrome: mental subnormality and nasal papillomata. Aust Paediatr f 1977;13:114-18.

3 Der Kaloustian VM, Moroz B, McIntosh N, Watters AK, Blaichman S. Costello syndrome. Am $\mathcal{f}$ Med Genet 1991;41:69-73.

4 Martin RA, Lyons Jones K. Delineation of Costello syndrome. Am F Med Genet 1991;41:346-9. 
5 Say B, Gucsavas M, Morgan H, York C. The Costello syndrome. Am f Med Genet 1993;47:163-5.

6 Teebi AS, Shabaani IS. Further delineation of Costello syndrome. Am $\mathcal{F}$ Med Genet 1993;47:166-8.

7 Philip N, Mancini J. Costello syndrome and facio-cutaneous-skeletal syndrome. Am $\mathcal{f}$ Med Genet 1993;47:174 5.

8 Zampino G, Mastroiacovo P, Ricci R, et al. Costello syndrome: further clinical delineation, natural history, genetic definition, and nosology. Am $\mathcal{f}$ Med Genet 1993;47:176-83.

9 Borochowitz Z, Pavone L, Mazor G, Rizzo R, Dar H. New multiple congenital anomalies: mental retardation syndrome (MCA/MR) with facio-cutaneous-skeletal involvement. Am $\mathcal{F}$ Med Genet 1992;43:678-85.

10 Martin RA, Lyons Jones K. Facio-cutaneous-skeletal syndrome is the Costello syndrome. $\mathrm{Am} \mathcal{7} \mathrm{Med}$ Genet 1993;47:169.

11 Der Kaloustian VM. Not a new MCA/MR syndrome but probably Costello syndrome? Am f Med Genet 1993; probably
12 Teebi AS. Costello or facio-cutaneous-skeletal syndrome? Am $\mathcal{F}$ Med Genet 1993;47:172.

13 Patton MA, Tolmie J, Ruthnum P, Bamforth S, Baraitse $M$, Pembrey $M$. Congenital cutis laxa with retarde growth and development. F Med Genet 1987;24:556-61.

14 Patton MA, Baraitser M. Cutis laxa and the Costello syndrome. $\mathcal{f}$ Med Genet 1993;30:622.

15 Sakati NO, Nyhan WL, Shear CS, et al. Syndrome of cutis laxa, ligamentous laxity, and delayed development. Pediatrics 1983;72:850-6.

16 Borochowitz Z, Pavone L, Mazor G, Rizzo R, Dar H. Facio-cutaneous-skeletal syndrome. Am f Med Genet 1993;47:173

17 Berberich MS, Carey JC, Hall BD. Resolution of the perinatal and infantile failure to thrive in a new autosoma recessive syndrome with the phenotype of a storage disorder and furrowing of ! the palmar creases. 11 th $\mathrm{DW}$ Smith workshop on malformation and morphogenesis, Lexington, Kentucky, 1990. Proc Greenwood Genetic Center 1991;10:98. 